\title{
LOS ORIGENES DEL PARTIDO COMUNISTA EN ALICANTE (1920-1923)
}

\author{
Francisco Moreno Sáez
}

\section{1. - ANTECEDENTES}

Sin descartar la importancia de las secuelas de la Primera Guerra Mundial -crisis de subsistencias, aumento de la sindicación, crecimiento de la conflictividad social, etc. - en la sociedad española de finales de la segunda década del siglo XX, parece obligado referirse, a la hora de plantear los antecedentes de la aparición del Partido Comunista en España, al impacto causado por la Revolución Rusa entre la clase obrera. Como es sabido, en un primer momento, la Revolución despertó mayor entusiasmo entre los anarcosindicalistas que entre los propios socialistas. Entre éstos, predominó al principio el temor a las repercusiones que la política pacifista de los nuevos dirigentes rusos podía provocar en el bando de los aliados, junto a cierta satisfacción por la caída del Imperio Zarista, único obstáculo a la identificación entre las potencias aliadas y la causa de la libertad y la democracia, que los aliadófilos trataban de hacer a toda costa.

Sin embargo, no faltaron actitudes, dentro del Partido Socialista español, contrarias a la aliadofilia de los dirigentes. Como ha señalado Carlos Forcadell (1), ya habían surgido en el seno del socialismo español serias discrepancias - aunque perfectamente controladas por el "aparato» - sobre el desarrollo de la Conjunción Republicano-Socialista y sobre la actitud del Partido ante la Guerra Mundial. Así las cosas, «el

(1) FORCADELL, Carlos, Parlamentarismo y bolchevización. El movimiento obrero español. 1914-1918. Crítica. Barcelona 1978. 
hecho fundamental que se va a añadir a la delimitación de las líneas de fractura en el socialismo español va a ser la revolución rusa de 1917».

En agosto de 1918, el sector crítico y minoritario del Partido Socialista - del que formaban parte García Cortés, Núñez de Arenas, Virginia González, Lamoneda, Egocheaga y García Quejido- decide publicar un semanario para exponer sus posiciones, y en el aniversario de la huelga general de 1917, para recordar simbólicamente el carácter revolucionario que había de tener el socialismo, aparece en Madrid «Nuestra Palabra», que toma su título del periódico publicado en París por León Trostki, poco antes. Entre los colaboradores de este semanario, que ha sido llamado por Meaker (2) «la cuna del Partido Comunista español», figuraban dos hombres ligados al socialismo alicantino. Se trataba de José Verdes Montenegro y Rafael Millá. El primero habia sido, desde principios de siglo hasta precisamente ese verano - fecha en que había obtenido su traslado a Madrid - , catedrático de Psicología y Etica en el Instituto de Enseñanza Media de Alicante; era un intelectual de cierta altura (3), buen conocedor del marxismo - aunque con unas concepciones muy rígidas - , traductor de Federico Engels y Enrique Ferri, inspirador del semanario socialista alicantino «El Mundo Obrero» (1901-1905), etc; Verdes Montenegro era, pues, hombre importante dentro del Partido Socialista, aunque estaba enfrentado, por su.actitud internacionalista y sus críticas a la Conjunción, con los dirigentes del partido, en especial con Julián Besteiro. En cuanto a Rafael Millá Santos, había nacido en Alicante en 1891 y había entrado en contacto con el socialismo a través precisamente de las páginas de «El Mundo Obrero", que se tiraba en la imprenta en la que Millá trabajaba como aprendiz; perteneció a la Sociedad Tipográfica, y a la Juventud y Agrupación

(2) MEAKER, Gerald H., La izquierda revolucionaria en España. 1914-1918. Ariel. Barcelona. 1978. El primer número de «Nuestra Palabra» (6 agosto 1918), en el que figuraban los colaboradores de la publicación, se puede leer en la Hemeroteca Municipal de Madrid. La tirada de esta publicación osciló entre los 1.200 y los 4.000 ejemplares.

(3) Se relacionó, a través de la amistad o de la polémica, con los hombres de là generación de 98, como Azorín (VALVERDE, J.M. Azorín. Planeta. Barcelona. 1971), Ramiro de Maeztu (ABELLAN, J.Luis, Ramiro de Maeztu o la voluntad de poder. En el volúmen de homenaje a Pérez de la Dehesa publicado por Ariel. Barcelona. 1975), Valle Inctán (HORMIGON, J.A. Valle Inclán: política, cultura, el realismo y el pueblo. Comunicación. Madrid. 1972), etc. Verdes Montenegro colaboró también en «Germinal» (RAMOS GARZON, A. , La revista Germinal y los planteamientos estéticos de la gente nueva, en el citado libro en homenaje a Pérez de la Dehesa) y en los diarios "El País» y «El Imparcial», en la última década del siglo XIX (PEREZ DE LA DEHESA, R. El grupo Germinal: una clave del 98. Taurus. Madrid. 1970), intercambió correspondencia con Unamuno, etc. Sobre Verdes puede verse el libro de TUÑON DE LARA, M., Medio siglo de cultura española. 18811936. Tecnos. Madrid. 1973. $3^{\mathrm{a}}$ edición. 
Socialista de Alicante, organismos en los que muy pronto ocupó cargos dirigentes (4).

Precisamente estos dos hombres, Millá y Verdes Montenegro, van a acudir al XI Congreso del Partido Socialista, en noviembre de 1918, en representación de la Agrupación de Alicante, que contaba con 30 afiliados, y que les encomendó especialmente defender el criterio de "estar conformes con la revolución rusa, o sea el bolcheviquismo» (5). En el Congreso, Millá - que llevó la voz cantante del sector críticoatacó a «El Socialista» por su aliadofilia y porque «no se ha prestado a la Revolución maximalista de Rusia el calor y la adhesión que ha debido merecer un movimiento que no ha sido sólo antigermánico y antiimperialista, sino también una rebeldía contra las clases poderosas de Rusia». (6). Estas acusaciones de Millá provocaron una rectificación de Besteiro y una resolución del Congreso en que se saludaba a la Revolución Rusa como «el triunfo del espíritu revolucionario del proletariado, que ha de transformar el mundo implantando el régimen socialista».

Mientras se celebraba el Congreso del Partido Socialista, la Juventud Socialista de Alicante - que presidia Emilio Requena, uno de los futuros fundadores del Partido Comunista alicantino - acordaba publicar en el diario republicano «El Luchador» una serie de artículos sobre el origen, desarrollo y finalidad de la Revolución Rusa, para que se supiese en qué consistía «el bolchiviquismo... que tanto horroriza al capitalista, que ha espantado a la burguesía, por lo que nos satisface» (7). La serie, que pretendía contrarrestar «las mentiras y calumnias de los periódicos clericales y burgueses", no llegó a publicarse, pero es una clara prueba de la actitud de los jóvenes socialistas alicantinos que, en su asamblea general de diciembre de 1918, manifestaban su simpatía por la Revolución Rusa, "o sea el Bolchiviquismo, que son los verdaderos socialistas» (8).

En cuanto al resto de la provincia, tenemos alguna noticia sobre el impacto de la Revolución Rusa - que estaba ya pasando a ser considerada por la clase obrera como un «modelo» trasplantable a España - en Elche, donde el Partido Socialista estaba sólidamente implantado. Cu-

(4) Se equivoca Vicente Ramos (Historia de la guerra civil en la provincia de Alicante. I. Págs. 147-148), al asegurar que Millá había ingresado en las Juventudes Socialistas en 1914, pues con anterioridad había ocupado cargos en la Agrupación Socialista, que presidia en 1918. Posteriormente, Millá fue alcalde de Alicante durante la guerra civil y murió después en la URSS.

(5) «El Luchador», 20 noviembre 1918./ «E| Socialista», 24 noviembre 1918.

(6) «El Socialista», 25 noviembre 1918.

(7) «El Luchador», 21 noviembre 1918.

(8) «El Luchador», 2 diciembre 1918. Se acordó también «felicitar a los periódicos Nuestra Palabra y República Social, que defienden a los compañeros rusos». 
riosamente, la primera referencia elogiosa a lo sucedido en Rusia que aparece en el semanario "Trabajo" - órgano de la Agrupación y la Juventud Socialista locales y de las Sociedades Obreras afectas a la UGT e instaladas en el Círculo Obrero llicitano- se debe a la pluma de un sindicalista, Francisco Navarro, que solicita su ingreso en el Partido Socialista por haberse convencido de la necesidad de la acción política precisamente por el ejemplo de los rusos, «siéndome grato el programa, eminentemente socialista, presentado al pueblo ruso por los Trosqui y Lenine» (9).

En los primeros meses de 1919 van llegando a la prensa de izquierdas mayores datos sobre lo sucedido en Rusia, e informaciones sobre los personajes y las teorías alli triunfantes. (10). De otro lado, y de acuerdo con una iniciativa de "Nuestra Palabra» (11), se organizan en diversos lugares de la provincia mítines donde hombres como Daniel Anguiano o Rafael Millá ponen de relieve las características de la Revolución Rusa, a la que se compara con la Comuna de París: ante la enorme conflictividad social que está teniendo lugar en España durante 1919, parece inminente el estallido de un proceso revolucionario semejante al ruso. Finalmente, hay que señalar que los sectores «bolchevizantes» se lanzan a la búsqueda de medios de expresión y propaganda propios: en Alicante, en febrero de 1919, se habla de la pronta aparición de un semanario "dedicado a la propaganda bolcheviquista", titulado "Conciencia Obrera», que no llegaría a aparecer. (12). En Alcoy, en marzo, se anuncia la aparición de "La Bandera Roja», semanario "de tendencias bolchevistas» (13): sin embargo, la deportación de toda su redacción con ocasión de la huelga general de finales de marzo, interrumpió muy pronto la publicación de "La Bandera Roja» - en cuya redacción figuraban los hombres más destacados del socialismo alcoyano, dirigidos por Santiago Gadea-, que dejó de publicarse en junio (14).

(9) «Trabajo», 31 marzo 1918.

(10) Entre enero y febrero de 1919, se publican en "Trabajo» los siguientes artículos sobre el tema: SCHTSCHUKIN, Elena, Precursores de la Revolución Rusa: Ios dekabristi / VERFEUIL, Raoul, Socialismo y democracia / Lenine (biografia anónima) / GARCIA CORTES, Mariano, Los bolchevikis en París. La gran victoria.

(11) A primeros de 1919, "bajo los auspisios de Nuestra Palabra se celebraron numerosísimos mítines pro-bolcheviques, en los cuales los nuevos dirigentes rusos eran elogiados $y$ defendidos con gran calor ante auditorios cada vez más numerosos y entusiastas) (MEAKER, op. cit. pág. 275).

(12) «El Luchador», 12 febrero 1919.

(13) "El Socialista», 10 marzo 1919.

(14) «El Socialista», 18 abril 1919. (La Bandera Roja) y 18 junio 1919 (Desde A/coy. La suspension de la Bandera Rojal. 
La creación, en marzo de 1919, de la Tercera Internacional, como consecuencia de la creencia de los bolcheviques rusos en un inmediato derrumbe de la sociedad capitalista y en la necesidad, por tanto, de crear una nueva organización internacional de partidos obreros que, tras destruir a la reformista II Internacional, dirigiese al proletariado en su camino hacia la toma del poder, va a dar armas a los sectores más radicalizados del Partido Socialista, que aspiraban a implantar en España las tácticas soviéticas, ante la agitación social reinante y el auge de los sindicalistas. Por el contrario, para los sectores más moderados del Partido, la aparición de la III Internacional representaba la necesidad de sustituir las platónicas manifestaciones de solidaridad con la Revolución Rusa por una modificación auténtica en la táctica, que se había vuelto más prudente desde el fracaso de la huelga de agosto de 1917 (15).

Desde mediados de 1919, los sectores más radicalizados, que ya comenzaban a llamarse "terceristas» o "bolchevikistas», realizan una intensa labor de propaganda y agitación que, al tiempo que una glorificación de la Revolución Rusa, suponía también una clara crítica de la línea seguida por el «aparato» dirigente del PSOE y de la UGT. Sin embargo, no hay una clara oposición por parte del "aparato" a estos avances "bolchevikistas», y en los mítines se exaltaba a los revolucionarios rusos, se condenaban los asesinatos de Rosa Luxemburgo y Karl Liebcknecht, se elogiaba a los húngaros, etc. (16). En la provincia de Alicante continúa siendo Rafael Millá - que habla en diversos mítines en Torrevieja, Petrel, Alicante, etc. - el líder indiscutible de este sector. De otro lado, conviene tener en cuenta que en ese año de 1919 los sindicalistas habían conseguido una extraordinaria movilización de la clase obrera de Alcoy, Alicante y comarcas como La Marina, por lo que representaban un peligro grave para la hegemonía socialista. $Y$ si bien los sindicalistas, en esos momentos, se vuelcan en elogios de la Revolución Rusa, sostienen fuertes enfrentamientos con Rafael Millá, al que acusan, no sin cierta razón, de afirmar que las transformaciones sociales han de reali-

(15) Sobre la III Internacional y sus efectos, pueden verse los libros de COLE, G.D.H., Historia del pensamiento socialista. $V$ y VI. Comunismo y socialdemocracia. Fondo de Cultura Económica. México. 1974/DEL ROSAL, Amaro, Los Congresos Obreros Internacionales en el siglo XX. Grijalbo. Barcelona. 1975/ESTRUCH, Joan, Historia del Partido Comunista de España. 1920-1939. El Viejo Topo. Barcelona. 1978.

(16) Por ejemplo, mítin en Elche en enero de 1919 ("Trabajo», 2 febrero 1919), a consecuencia del cual son procesados varios jóvenes socialistas por haber reproducido, en la convocatoria, un artículo publicado en "Nuestra Palabra» («Trabajo», 9 febrero 1919)/ Daniel Anguiano habla en Alicante sobre el tema ("Diario de Alicante», 2 agosto 1919)/Véase tambiém el artículo de José Navarro González, La lucha de clases se va acentuando cada vez más, en "Trabajo», 14 septiembre 1919. 
zarse violentamente y criticăr, al mismo tiempo, las tácticas de «acción directa" empleadas por los sindicalistas (17).

Entre el 9 y el 16 de diciembre de 1919 se celebró en Madrid un Congreso Extraordinario del Partido Socialista para tratar la cuestión de las Internacionales. Por la provincia de Alicante asiste Rafael Millá - en representación de las agrupaciones de Alicante, San Juan y Hondón de las Nieves - , en tanto que otras agrupaciones delegan su representación: la de Elche, en Verdes Montenegro, y varias del Medio y Alto Vinalopó, en el valenciano Francisco Sanchis (18). Como se sabe, los "terceristas» recomendaron el ingreso sin reservas en la III Internacional, en tanto que la mayoría de la Ejecutiva proponía mantenerse en la II, sin ahorrar elogios a la Revolución Rusa e incluso admitiendo la necesidad de la dictadura del proletariado, dictadura que había de variar «según el grado de desarrollo y perfeccionamiento industrial de las distintas naciones», ya que sería un grave error "la imitación servil de los procedimientos empleados en una nación determinada para hacer valer la fuerza del proletariado". En la discusión sobre el tema, Verdes Montenegro aseguró que la II Internacional había quedado ya destruida por la guerra y que, se votase lo que se votase, la III Internacional se impondría. Tras un enfrentamiento con Besteiro, Verdes se retiró del Congreso y anunció su baja en el Partido (19). Como es sabido, el Congreso acordó ingresar en la III Internacional, si se fracasaba en el intento de conseguir la unidad del proletariado mundial en el inmediato Congreso de la II Internacional.

En ese mismo mes se celebró, también en Madrid, un Congreso de las Juventudes Socialistas. Por la provincia de Alicante participaron representaciones de Villena, Alicante, Crevillente y Elche: esta última era la más numerosa, con 120 afiliados, y envió al estudiante Ginés Ganga y a Antonio Cañizares, hombre ya plenamente identificado con el «aparato» de la UGT local. El Congreso acordó la adhesión a la III Internacional, por inmensa mayoría. En la discusión, Cañizares recomendó, sin éxito, que «se ratifique el acuerdo que acerca de esto ha tomado el Partido» (20).

A fines de 1919, pues, la práctica totalidad de la clase obrera - la CNT, tras el Congreso de la Comedia, las Juventudes Socialistas, el propio Partido Socialista, con reservas - e incluso algún sector de la pe-

(17) «Reivindicación», 3 agosto 1919.

(18) «El Socialista», 9 diciembre 1919.

(19) Verdes Montenegro no se incorporó al Partido Comunista y se mantuvo alejado de la política activa, aunque cercano al socialismo.

(20) «El Socialista», 16 y 17 diciembre 1919. 
queña burguesía progresista, como el Partido Republicano Catalán -que animaban Marcelino Domingo, Francesc Layret y Lluis Companys -, estaban adheridas a la III Internacional.

\section{LA CREACION DEL PARTIDO COMUNISTA ESPAÑOL}

Por estas fechas llegan a España, un tanto circunstancialmente, los agentes de la Komintern Michael Borodin, Roy y Ramírez. Borodin sostiene en Madrid diversas entrevistas con dirigentes socialistas partidarios de la III Internacional, como Lamoneda, Nuñez de Arenas o García Cortés, y en enero de 1920 abandona España. Aunque hay algunas dudas sobre ello (21), parece que Borodin se mostró dispuesto a provocar de inmediato una escisión «tercerista» en el seno del Partido Socialista. Según Comín Colomer, Borodin se entrevistó también con Rafael Millá y con dirigentes de las Juventudes Socialistas (22). A fines de enero de 1920 se constituye en Madrid un "Grupo Pro-Tercera Internacional» - donde figuran, entre otros, Daniel Anguiano, secretario del Partido, y López y López, dirigente de las Juventudes - para «laborar por la incorporación rápida del Partido a la Tercera Internacional».

Entre tanto, el mexicano Ramírez trabajaba con las radicalizadas Juventudes madrileñas para conseguir la inmediata aparición de un Partido Comunista. Según relata uno de los miembros del Comité Nacional de la Federación de JJ.SS., Luis Portela (23), el Comité conspiraba para tal propósito. Aunque el tema es todavía muy confuso, creemos - de acuerdo con lo sucedido en Alicante - que la actuación de los agentes de la Komintern se dirigió, en un primer momento, a convencer a Daniel Anguiano para que, con el apoyo de las Juventudes, «asumiese la secretaría general del Partido que nos proponíamos crear y nos había dado su conformidad», según Portela. Las dudas de Anguiano forzarían al Comité de la Federación de Juventudes a actuar por su cuenta, poco después. La situación culminó, como se sabe, de forma un tanto rocambolesca: el Comité Nacional envió a las Juventudes de todo el país dos cartas; la primera disponía que se celebrasen asambleas el día 15 de abril (24) y pedía que se leyese en ellas la segunda carta, que no se podía

(21) MEAKER, op. cit. Págs. 330-332.

(22) COMIN COLOMER, Eduardo, Historia del Partido Comunista de España.l. Editora Nacional. Madrid. 1967. $2^{\mathrm{a}} \mathrm{ed}$.

(23) PORTELA, Luis, 1920. Asi fundamos el Partido Comunista Español, en «Nueva Historia», julio de 1978.

(24) «El Socialista» del 14 abril 1920 convocaba la asamblea de la Juventud madrileña «para tratar de un asunto grave comunicado por circular del Comité de la Federación $\mathrm{Na-}$ cional de Juventudes». 
abrir hasta entonces y en la cual se declaraba que las Juventudes Socialistas se convertían en el Partido Comunista Español. Este pronunciamiento tuvo éxito en Madrid (25), pero escaso eco en provincias. Según algunas fuentes, la mitäd de los efectivos de las Juventudes, unos dos mil afiliados, pasaron al nuevo Partido (26).

En Alicante, las cosas sucedieron de forma algo distinta. En primer lugar, hay que señalar que siguieron ganando posiciones dentro del Partido Socialista los "terceristas», como se puede apreciar en mítines (27) y artículos de prensa (28). En abril, José López - tercerista, pero que en la asamblea no secundará la escisión, prefiriendo esperar al Congreso del Partido - realiza una gira de propaganda por Jumilla, Villena, Elche y Crevillente «para explicar las consecuencias que para el rápido triunfo del socialismo ha de tener la Revolución Rusa» (29). Pese a ello, todos los indicios parecen demostrar que el pronunciamiento de la Juventud Socialista no tuvo eco en la provincia de Alicante. En Elche, el semanario socialista "Trabajo» no hace referencia alguna al tema, y en el resto de las Juventudes alicantinas predominaba una postura moderada: así lo indican las adhesiones a Largo Caballero - que había sido atacado por el Comité Nacional de la Federación de las Juventudes - enviadas por las organizaciones de Villena, Alcoy y Onil (30). El único lugar en que la creación del Partido Comunista tuvo eco fue en la capital, aunque los hechos se produjeron de forma distinta a otros lugares, tal vez por el peso dentro del Partido del sector tercerista.

En febrero de 1920 había reaparecido el semanario socialista alicantino «El Mundo Obrero». En su primer número, la redacción justificaba el hecho por la necesidad de contar con un lugar de discusión ideológica en momentos tan importantes: «Estamos viviendo horas revoluciona-

(25) "El Socialista», 17 abril 1920, convoca a los jóvenes socialistas madrileños «para examinar la situación que les crea la constitución de un Partido Comunista en Madrid».

(26) MEAKER, op.cit. págs. 334-335/No se trató, pues, de una asamblea o Congreso general de las Juventudes Socialistas, como afirmaba la oficial Historia del Partido Comunista de España, pág. 26, o más recientemente DEL ROSAL, Amaro, Consideraciones y vivencias sobre la fundación del P.C.E. y sus primeros años, en la serie publicada por la Fundación de Investigaciones Marxistas, Sesenta años en la historia del Partido Comunista de España, pág. 68.

(27) Mitines en Elche, con Vicente Barrio («Trabajo», 14 marzo 1920) y José López («Trabajo), 26 marzo 1920).

(28) En "Trabajo" se publican artículos de BASILIO, Para los jóvenes socialistas. Energias para el triunfo (1 febrero 1920)/ELISEO DEL CISNE, Rápida (11 abril 1920)/ NIN, Andrés, La actualidad social. Notas y comentarios ( 3 marzo 1920), quien asegura que muy pronto los sindicalistas aceptarian la acción política, pues aspiraban al comunismo.

(29) «El Socialista», 6 abril 1920.

(30) «El Socialista», 10, 19 y 24 abril 1920. 
rias, y como elementos revolucionarios que somos, queremos poner al servicio de la causa del pueblo, lo mejor de nuestras actividades, de nuestros entusiasmos, de nuestros amores» (31). A través de los escasos números que se publicaron, los «terceristas» alicantinos, sobre todo Emilio Requena, Francisco Castelló Fayos y Rafael Millá, realizaron una constante defensa del «modelo» bolchevique y de la dictadura del proletariado:

«El proletariado alicantino, el proletariado español, el proletariado universal, debe aspirar, tiene que aspirar a importar de la Rusia bolchevista todo lo grande, todo lo bueno que las masas obreras han hecho, para de una vez para siempre romper las cadenas que nos atan, quebrar el látigo que nos azota y demoler todo cuanto existe por caduco y carcomido, y levantar sobre sus escombros los cimientos de una sociedad más justa y más humana» (32).

Ahora bien, este convencimiento coexistía con rasgos de la ideología tradicional del sector más moderado del partido socialista, sobre todo, con la advertencia a las clases dirigentes de que es necesaria la evolución para evitar la revolución. Así, comentando unos sangrientos sucesos provocados en Alicante por la crisis de subsistencias, un editorial de «El Mundo Obrero» decía lo siguiente:

«Preferimos que acierten en su gestión nuestros enemigos, aún a trueque de que su posición se afirme con el éxito, antes de ver pasar a nuestro pueblo por el dolor de que sangre proletaria y alicantina bañe las calles de la ciudad. Revolucionarios de verdad, queremos, sin embargo, que los momentos actuales, precursores de la revolución que se avecina, sean lo menos cruentos posibles»" (33).

No hay, creemos, en las páginas de "El Mundo Obrero» una clara comprensión de lo que supone, a nivel teórico y práctico, el bolchevismo, sino más bien un total voluntarismo, un entusiasmo sin límites, pues se piensa que "ha llegado la hora del proletariado", como «lo dice Italia con sus 150 diputados socialistas, Inglaterra con los contínuos triunfos del partido laborista y el llamamiento de Lloyd George a todas las fuerzas capitalistas para formar el cuadro con

(31) Al reanudar la publicación, editorial de «El Mundo Obrero», 14 febrero 1920.

(32) REQUENA, Emilio, „Por la Rusia de los Soviets! («El Mundo Obrero», 14 febrero 1920) / Muy interesante resulta la polémica - que reproducimos en el apéndice - entre MIGUEL, Machaconerias («El Mundo Obrero», 10 abril 1920) y MILLA, Defensa de la Dictadura («El Mundo Obrero», 17 abril 1920),sobre la dictadura del proletariado.

(33) Las subsistencias. El pasado y el presente. Lo que puede ocurrir. Nuestra leal advertencia. El cumplimiento del deber. Editorial de "El Mundo Obrero», 13 marzo 1920. 
que oponerse al próximo asalto al poder del proletariado inglés; Alemania con su actual revolución marcadamente obrerista, proclamando los soviets en las grandes ciudades industriales; España con la reciente victoria electoral del Partido Socialista y el formidable acrecentamiento de las fuerzas de la Unión General; lo dice, por último, Rusia con el afianzamiento definitivo de la República Socialista, contra la que no han podido todas las infamias juntas que el egoismo capitalista ha acumulado para vencerle ni todas las fuerzas militares con que pretendia extrangularla (sic)»" (34).

Este grupo que animaba «El Mundo Obrero» (35) fue el que protagonizó la primera escisión comunista en Alicante. El día 17 de abril de 1920, el diario «El Luchador» publica la noticia de la constitución en Alicante del Partido Comunista Español, en el que figuraban «nuestros buenos amigos e ilustrados obreros Rafael Millá y Francisco Castelló Fayos» y que estaba dirigido, a nivel estatal, por Daniel Anguiano - lo cual parece confirmar lo apuntado sobre el primer intento promovido por la Komintern, más arriba señalado- (36). En el mismo número aparecía un artículo titulado "Se ha creado el Partido Comunista», que firmaba "Un socialista» y que probablemente se debía a la pluma de Millá. Antes de reproducir las Bases del nuevo Partido (37), se hablaba del proceso de formación del mismo:

"Hoy, día de la fecha» - 15 de abril, aunque se publicó dos días más tarde - «se habrá proclamado de una forma pública la fundación del Partido Comunista. Los encargados directamente de esta misión, por parte de la III Internacional en Moscou, ha sido la Federación de Juventudes Socialistas. En la visita que el delegado directo bolcheviki, Boroden, hizo recientemente a Madrid, dejó el encargo de la fundación de este nuevo Partido Revolucionario por considerar que el actual Partido Socialista no cumplia en su ac-

(34) La hora del proletariado, editorial de "El Mundo Obrero», 27 marzo 1920.

(35) El semanario se dejó de publicar en Mayo «por motivos económicos y de orden interno», según "El Luchador», 6 mayo 1920.

(36) Los Comunistas en Alicante. en "El Luchador», 17 abril 1920.

(37) Las bases son conocidas - pueden verse en ARTOLA, Miguel, Partidos y programas políticos. 1808-1936. Aguilar. Madrid. 1974-y entre ellas destacan la adhesión a la III Internacional, el rechazo de la II "por traidora», la negativa a plantear reformas mínimas, el calificativo de «reformista» aplicado al PSOE, «la creación de una organización soviética que reuna las fuerzas revolucionarias de la UGT y la CNT dentro del Partido Comunista" y el «reconocimiento de la dictadura del proletariado como único medio de organizar la sociedad comunista... y de los soviets o consejos de Rusia como órganos de ejecución de esa dictadura». 
tuación con lo que se requiere de impulso revolucionario dentro de la III Internacional. Este grupo primeramente nombrado fue relevado de su encargo, porque vieron desde Rusia, que no cumplía activamente su misión. Se confirieron poderes y confianza a la Federación de Juventudes Socialistas que, como hemos dicho, ha sido la que ha proclamado la fundación del nuevo Partido».

El carácter claramente exógeno de la fundación del Partido quedaba explicitado en este mismo artículo, cuando su anónimo autor advertía:

«En lo que se refiere a los motivos que los bolchevikis rusos han tenido para tomar esta determinación en España, los encargados de estos trabajos en Alicante, ya harán públicas las causas por medio de un manifiesto tan pronto como se haya creado la Agrupación Comunistay.

No se celebró, pues, en Alicante la asamblea de la Juventud Socialista, que tal vez estuviese en esos momentos desorganizada. Pero se cumplió, en cierta medida, el acuerdo de dar a conocer en la fecha acordada la constitución del nuevo Partido. El día 18 se presentaba en la Junta General de la Agrupación Socialista de Alicante la siguiente propuesta:

"Los que suscriben, afiliados a esta Asociación, proponen a la misma acuerde

1. Que esta Asociación cause baja en el llamado Partido Socialista Obrero.

2. Declare su conformidad con el Manifiesto Programa del Partido Comunista Español.

3. Acuerde pedir inmediatamente su ingreso en el llamado Partido Comunista Español.

4. Reforme el reglamento interno de esta entidad, adaptándolo a las exigencias de esta transformación.

Alicante, a 18 de abril de 1920. Rafael Guerra, Emilio Requena, Rafael Millá y Francisco Castelló Fayos» (38).

La asamblea de la Agrupación alicantina, constituida por una treintena de afiliados, acordó aplazar la decisión hasta una nueva reunión, para que todos pudiesen estudiar el programa del nuevo partido. El 9 de mayo, se rechazó la propuesta y sus cuatro firmantes abandonaron el Partido Socialista y se constituyeron en comisión organizadora del Partido Comunista Español, pidiendo «a todos los que estén de acuerdo con el Manifiesto-Programa envien su adhesión a la Casa del Pueblo,

(38) «El Luchador», 28 abril 1920. 
expresando nombre y Sociedad Obrera a la que pertenecen. La Comisión convocará a todos para la definitiva constitución» (39).

\section{LA APARICION DEL PARTIDO COMUNISTA OBRERO ESPAÑOL}

En general, el nuevo Partido, llamado «de los cien niños», no representó un problema importante en el Partido Socialista, donde seguía el debate entre los «terceristas» y los sectores más moderados, con predominio, al menos así lo parecía, de los primeros. Con ocasión del Primero de Mayo se publicó en Elche - en Alicante no fue autorizada su difusión - una hoja con elogios a la Revolución Rusa y proponiendo el ingreso en la III Internacional. $Y$ entre las peticiones obreras de esa fecha figuraba la de que se concertase la paz con la República de los soviets y se pusiese fin a toda intervención armada. Al propio tiempo, se protestaba «contra quienes han ahogado en sangre el movimiento comunista en Alemania y Hungría» (40). En la prensa socialista se insistía en la necesidad de continuar luchando.

«...hasta poder conseguir, en suma, la metamorfosis del régimen actual, lleno de monstruosidades, por el nuestro, implantando la deseada dictadura proletaria, con el establecimiento del régimen comunista, del régimen socialista» (41).

Por su parte, los sectores más moderados reconocían la importancia de la Revolución Rusa, pero insistían en la posibilidad de no tener que llegar a tales extremos, si la burguesía atendía a razones y admitía ciertas reformas que posibilitasen una evolución (42).

Se llega así, en el verano de 1920, a los Congresos extraordinarios del Partido Socialista y la Unión General de Trabajadores, convocados precisamente para dirimir la cuestión de las Internacionales. En el Congreso del Partido se acordó la adhesión condicionada a la III Internacional y se envió a Moscú a Daniel Anguiano y Fernando de los Ríos para obtener una mayor información. Ante el avance de los «terceristas», ésta fue la única solución que encontraron los sectores más moderados, que domi-

(39) «Diario de Alicante», 10 mayo 1920/ «El Luchador, 17 mayo 1920.

(40) «El Luchador», 3 mayo 1920.

(41) "Trabajo», 1 mayo 1920 /En "El Socialista» aparecen textos de Lenin, Zinoviev y Radek, y se hacen elogios de la lucha de Hungria y Baviera, según GARCIA VENERO, M., Historia de las Internacionales en España. II. Pág. 350.

(42) CAÑIZARES, Antonio, Contra la Rusia socialista. La burguesía y el proletariado mundial, en "Trabajo», 23 mayo 1920, advierte a los "opresores del mundo" de que, si atacan a la Rusia soviética, acelerarán la revolución mundial. 
naban en gran medida el «aparato» y que consiguieron que el Congreso de la UGT acordase la permanencia en la Internacional de Amsterdam (43).

En julio de 1920 se celebró en Moscú el Il Congreso de la Internacional Comunista, que aprobó las llamadas «21 condiciones» para los nuevos ingresos. A este Congreso asistieron algunos representantes del Partido Comunista Español, que venía reduciendo prácticamente su actividad a la crítica de los "terceristas" que se mantenían en el Partido Socialista, en un ejemplo perfecto de lo que se podría denominar «el síndrome del escindido». En la provincia de Alicante, Rafael Millá era el único representante público del nuevo Partido y trataba de dar a conocer su programa en diversas charlas - que versaban sobre "La bancarrota de la democracia» o "Ideología y táctica de la III Internacional», por ejemplosin demasiado éxito, según la prensa local.

El regreso de Fernando de los Ríos y Anguiano, y la noticia de la existencia de las 21 condiciones provocaron una reacción entre los sectores más moderados del socialismo español, que ha sido bien descrita por Luis Arranz (44): se aceptaba el mito de la Revolución Rusa e incluso la dictadura del proletariado $y$ algunos otros principios teóricos, pero se hacía hincapié en la necesidad de una fase de preparación del proletariado para la revolución, lo que equivalía, prácticamente, a seguir la línea tradicional del socialismo español, es decir, insistencia en la necesidad de preservar dentro de la legalidad a las organizaciones del partido y del sindicato, intervención en las elecciones, búsqueda de mejoras económicas y legislativas, etc. La aparición de los llamados «Reconstructores», vía media entre la Internacional soviética y la desprestigiada II Internacional, supuso un respaldo internacional a esta postura.

Estas características se pueden encontrar en las páginas del semanario "Trabajo", que controlaba el aparato de las sociedades obreras ilicitanas, afectas a la UGT: se acepta el mito de la Rusia soviética (45), a la

(43) Entre los escasos delegados al Congreso se cuentan Rogelio Cantó, por Alcoy; V. Cerdá, por Castalla; M. Amat, por Elda, Petrel, Novelda y Monóvar; Francisco Lucio y Angel Martínez, por Alicante. La delegación de Villena la ostentaba M. Pedroso («El Socialista», 21 junio 1920). La única intervención fue la de Angel Martínez, que asegura que «se debe ir a Ginebra para eliminar a los traidores y constituir una Internacional verdadera", pero «no le parece bien que se integre en la III Internacional de un modo prematuro» («El Socialista», 25 junio 1920).

(44) ARRANZ, Luis, en la edición de los escritos de Pablo Iglesias (II Tomo. pág. 291) Publicada por Ayuso, Madrid. 1975.

(45) Una formulación literaria de este mito: ;Rusia!, que firma JUAN DE CASTILLA en "Trabajo», 7 noviembre 1920. 
que se cantan himnos (46), pero se pone de relieve la esperanza de que la clase dominante abandone posturas cerriles - que se ejemplifican en la actuación de La Cierva en Murcia (47) - para evitar que se pueda llegar a situaciones como la rusa.

Como es sabido, a finales de 1920, los anarcosindicalistas habían comenzado a marcar claramente sus diferencias con la Revolución rusa, como consecuencia de un mejor conocimiento sobre la forma en que se había producido: así, en Alcoy aparece un semanario titulado «El Comunista Libertario», cuya principal misión es combatir el bolchevismo y dejar en claro que nada tiene que ver con el comunismo libertario (48). Se perdía así un importante campo de acción para el nuevo Partido Comunista, a nivel estatal. Hay que tener en cuenta que, concretamente en Alicante, las relaciones entre los sindicalistas y Rafael Millá eran muy tensas, a raíz de unos imprudentes comentarios publicados por éste en "El Luchador» sobre la táctica de los sindicalistas, en enero de 1920, cuando precisamente los líderes cenetistas alicantinos se encontraban en la cárcel o deportados, como consecuencia de la sistemática represión que el Gobernador Civil, Dupuy de Lome, con la colaboración de la burguesía local, había lanzado contra el Sindicato Unico de Alicante (49).

En el primer congreso del Partido Comunista Español, celebrado en marzo de 1921, es elegido Rafael Millá miembro del Comité Central. En abril de ese año se celebró el Congreso Extraordinario del Partido Socialista en que se iba a consumar la escisión «tercerista». Al prestigio de Pablo Iglesias (50) y al control de la dirección de "El Socialista», los partidarios de la llamada «Internacional Dos y Media» unían sus sólidas posiciones en el «aparato» del partido. Para muchos socialistas, la acepta-

(46) El Coro Progreso de Elche, compuesto por socialistas o simpatizantes, estrena en enero de 1921 los himnos titulados «Rusia!» y "Frente Unico».

(47) BARCIA, Camilo, Lenin en Murcia, en «Trabajo», 23 enero 1921. Barcia, que era catedrático de la Universidad de Valladolid y había sido presentado como candidato a las elecciones a Cortes por la Agrupación Socialista de Elche, afirmaba que «este comunista de Murcia (La Cierva) está prestando a la causa rusa un inapreciable servicio».

(48) Pueden verse los artículos de este semanario, de corta duración, Bolchevismo no, comunismo si (6 noviembre 1920), Comunismo estatal y comunismo libertario (20 noviembre 1920), Bolchevismo y anarquia (27 noviembre 1920) y Dictadura y comunismo (3 enero 1921). El peseo de la campaña la llevaron los anarquistas alicantinos Juan Gomis y Cipriano Bertomeu.

(49) Nuestra posición ante el problema sindicalista, serie de artículos de Millá en «EI Luchador», del 15 al 31 de enero de 1920.

(50) Publica, poco antes del Congreso, en «El Socialista» artículos como No nos dividamos (28 marzo 1921), Sobre las condiciones tercera y quinta (4 abril 1921) y El fin de las 21 condiciones (9 abril 1921). 
ción de las 21 condiciones suponía el abandono de la acción política en instituciones como el Instituto de Reformas Sociales, los municipios o el Parlamento. De otro lado, el Congreso se celebró en un momento de claro repliegue de la clase obrera, en la represión subsiguiente al asesinato de Dato. Así las cosas, se votó mayoritariamente - tras oir los informes de Anguiano y De los Ríos - por la incorporación a la Internacional de los Reconstructores. Los terceristas se separaron del partido y crearon acto seguido el Partido Comunista Obrero Español (51).

¿Qué repercursiones tuvo en Alicante esta escisión? Antes del Congreso se había publicado en "El Socialista» (52) un manifiesto dirigido "A los socialistas españoles», que encabezaban Pablo Iglesias, Largo Caballero y Julián Besteiro, y en el cual se cantaban las excelencias de la Internacional de los Reconstructores: junto a socialistas de otras localidades, firman catorce alicantinos - entre ellos, Rafael Sierra, Angel Martínez, Francisco Lucio y, sorprendentemente, Francisco Castelló Fayos, que por tanto debió de haber abandonado muy pronto el Partido Comunista-, veintidós ilicitanos - entre ellos, Juan Barceló, José Vives, Antonio Lloret, Ginés Ganga y Antonio Cañizares, redactores todos ellos de "Trabajo" y dirigentes de los sindicatos locales - y veinticinco de Villena - entre ellos, los concejales José Cañizares y Maximiliano Silvestre-.

En el Congreso votaron por la Internacional de Moscú las Agrupaciones de Novelda y Crevillente. En cambio, por la de los Reconstructores, lo hicieron Alcoy, Alicante, Elche, Petrel, Pinoso y Villena. Se abstuvo la representación de Castalla (53). Como las agrupaciones de Crevillente y Novelda estaban representadas por Manuel Pedroso y Mariano García Cortés y no tenían, por tanto, representación directa, ignoramos si tras el Congreso llegaron a abandonar el Partido Socialista y a integrarse en el Partido Comunista Obrero Español, pues pudo darse el caso de ser Agrupaciones favorables a la III Internacional, pero no dispuestas a la escisión. Creemos más probable que se produjese en ambas agrupaciones un período de desconcierto y división: en Crevillente, la organización obrera atravesó un período de cierta desmovilización, aunque parece cierto que los comunistas siguieron con influencia en los

(51) Las manifestaciones de ios dirigentes socialistas y de los escindidos pueden leerse en La España politica del siglo XX, recopilación de documentos hecha por DIAZ-PLAJA, Fernando. Plaza-Janés. Barcelona. 1971.

(52) "El Socialista», 22 marzo 1921.

(53) "El Socialista», 25 abril 1921. Las representaciones más numerosas eran las de Elche y Castalla, con 100 afiliados cada una; y las menos, las de Crevillente, con 11 afiliados, Novelda y Petrel, con 25 afiliados cada una. 
sindicatos locales; en Novelda se produjo una división, pero lentamente se reconstruyó la Agrupación Socialista (54). En cuanto a otras localidades, sabemos que después del Congreso hubo asambleas socialistas en Hondón de las Nieves, Villena, Alicante, Elda y Monóvar, en las que se decidió la permanencia en el PSOE (55). Creemos totalmente equivocada la conclusión a que llega Salvador Franch (56), según la cual en Elche la escisión afectó a hombres como Barceló, Vives y Germán Penalva: ya hemos visto que los dos primeros firman el manifiesto a favor de los Reconstructores y sabemos que Barceló permaneció en el «aparato» de la UGT local; en cuanto a Germán Penalva, había sido expulsado del Partido en el Congreso celebrado en 1915 (57).

Aunque estamos poco informados de las repercusiones de la escisión, pensamos que el efecto fundamental fue un desencanto generalizado entre los militantes, lo cual, unido a la crisis de trabajo y al hecho de que el movimiento obrero se encontraba en un período de retroceso ante la reacción de la clase dominante, provocó el apartamiento de muchos hombres de la política activa. En «El Socialista» - que, ciertamente, trataría de minimizar la importancia de la escisión - se asegura que la atonía de las Agrupaciones y las Juventudes Socialistas en muchos lugares se debía más bien a la crisis de trabajo que al paso de militantes al Partido Comunista Obrero Español (58). Es evidente que muchas Agrupaciones Socialistas atravesaron una crisis muy grave, de la que comenzaron a recuperarse únicamente a partir de 1923: así, en febrero de ese año se reorganizó la de Elche - «después de sufrir el quebranto producido por la escisión comunista y la campaña de insidias

(54) En 1922 hay una conferencia del socialista valenciano Isidro Escandell; los socialistas se presentan a las elecciones municipales, colaboran en el periódico "Avante», etc.

(55) «El Socialista», 29 abril 12, y 13 mayo, 8 junio y 6 agosto 1921. Concretamente, la Agrupación de Elda hace constar que si bien su criterio era contrario al acordado en el Congreso, permanece en el PSOE por considerar que la escisión favorecería a la burguesía $y$ al gobierno. Naturalmente, "EI Socialista» no informa de las Agrupaciones que pudieron acordar su incorporación al PCOE.

(56) FRANCH, Salvador. Les crisis internes del PSOE al País Valencià, en el PRIMER CONGRESO DE HISTORIA DEL PAIS VALENCIANO. No sabemos en qué se basa para tal afirmación.

(57) Penalva estaba enfrentado con Vives desde la huelga de alpargateros de Elche de 1903. En el Congreso, el presidente de la comisión de conflictos preguntó a Penalva"usi retiraba las frases ofensivas para la citada colectividad (la Agrupación Socialista de Elche) que pronunció», y como contestara negativamente, quedó expulsado («El Socialista», 2 noviembre 1915).

(58) Se hace una referencia concreta a Alcoy, en este sentido, en «El Socialista», 26 enero 1922. 
y calumnias que estos elementos hicieron contra nuestros compañeros» (59) - , y en agosto, la de Monóvar (60).

La actitud de la prensa socialista ante la escisión fue, lógicamente, muy dura. Si en algún caso predominó la tristeza y el disgusto por haber visto «desertar de las filas socialistas a algunos elementos valiosos, dejando algo debilitado al bloque revolucionarion (61), en general abundaron los ataques personales y los insultos: asi, se critica a los que en Novelda habían abandonado el Partido y se les acusa de apoyar en las elecciones a los liberales (62), o se afirma que Joaquín Segura, líder de los comunistas ilicitanos y antiguo miembro de las Juventudes, se había apropiado de determinada suma, recogida para la editorial socialista (63). Como veremos, los comunistas adoptaion posturas semejantes, es decir, la sustitución de la discusión ideológica por el insulto personal.

Por su parte, la Federación de Juventudes Socialistas, que se había reconstituido tras el "golpe de mano» de abril de 1920, acordó, en un Congreso celebrado inmediatamente después del celebrado por el Partido, la adhesión a la Tercera Internacional y su conversión en Federación de Juventudes Comunistas, por 3.444 votos contra 440 . En este Congreso fueron precisamente los representantes de las Juventudes de la provincia de Alicante - sobre todo, Ginés Ganga, por la de Elchejunto al valenciano Escandell, los que más apoyaron la tesis de los Reconstructores, que acababa de triunfar en el congreso del Partido. Quedaban en Alicante las Juventudes de Villena, Elche y Alcoy: las dos primeras votaron por la Internacional de Viena, en tanto que la de Alcoy, que era partidaria de la III Internacional, no era favorable a la escisión y permaneció en las Juventudes Socialistas que, de nuevo, tuvieron que reorganizarse (64).

(59) «El Socialista», 16 febrero 1923/Nuestra organización socialista queda reorganizada, en «Trabajo», 11 febrero 1923.

(60) «El Socialista», 30 agosto 1923.

(61) ROMAN, Miguel. El abuelo y la escisión del Partido, en «Trabajo», 24 junio 1921. El semanario ilicitano no ofrece información sobre el Congreso de Abril y la escisión, por haber estado sin aparecer desde febrero a junio, suspendido arbitrariamente por el Gobernador Civil con ocasión de una huelga general de alpargateros.

(62) Primer acto revolucionario de los comunistas, en "El Socialista», 10 septiembre 1921.

(63) «El Socialista», 17 diciembre 1921.

(64) "El Socialista», 18 y 19 abril 1921/el 7 junio 1921 publica un manifiesto de la Federación de Juventudes Socialistas, que seguía existiendo, pese a la escisión. En ese mismo mes, asambleas de las Juventudes de Alcoy y Villena acuerdan seguir en la Federación socialista («El Socialista», 27 junio 1921). 


\section{EL PROCESO DE UNIFICACION DE LOS DOS PARTIDOS COMUNISTAS}

Según algunas fuentes, en el primer año de su existencia, el Partido Comunista Obrero Español llegó a tener 80 Agrupaciones y unos 6.500 afiliados, cifras que parecen muy exageradas. Sobre los nuevos partidos se ejercía una presión policíaca que ya no se ejercía sobre los socialistas - cosa que, evidentemente, pudo influir en la no incorporación a ellos de algunos socialistas y en su apartamiento de la militancia-, pues, como ha señalado Antonio Elorza (65) y como demuestra la prensa de provincias (66), la burguesía y las autoridades se aplicaron a crear la imagen de una revolución inminente, de la que consideraban indiscriminadamente protagonistas a anarquistas y bolcheviques. Según la historia oficial del Partido Comunista, tras el desastre del Annual «la policia detuvo a las dos direcciones de los dos Partidos Comunistas y a los dirigentes de la Juventud Comunista, la prensa del partido fue suspendida, los locales clausurados».

En el minúsculo Partido Comunista Español hay, a mediados de 1921, enfrentamientos entre los enemigos de toda actuación parlamentaria y los que opinaban lo contrario. Entre estos se contaba Rafael Millá, que argumentaba que «el antiparlamentarismo haría del Partido Comunista Español una caricatura del anarcosindicalismo, capaz de hacerle perder lo más esencial en él: el carácter político» (67). Ambas facciones, sin embargo, coincidian en su enemiga a los hombres del Partido Comunista Obrero Español, y en las primeras reuniones que hubo para tratar de la fusión - como consecuencia de una iniciativa de la Komintern - exigieron tener la mayoría en los órganos de dirección del nuevo partido y la exclusión de algunos miembros del PCOE, a los que consideraban reformistas.

Invitados ambos partidos comunistas al III Congreso de la Komintern - asistió, entre otros, Rafael Millá-, se llegó en Moscú a un principio de acuerdo y se decidió enviar a España a un agente de la Internacional,

(65) ELORZA, Antonio, Contexto histórico de la formación del Partido Comunista de España», en la citada "Sesenta años...», págs. 19-22.

(66) Algunos ejemplos de la prensa alicantina en «El Tiempo», 3 enero 1919 (Bolchevikis en España. Aumenta el peligro); "Diario de Alicante», 8 enero 1919 (¿Bolchevikis en alicante?); «El Día», 8 enero 1919 (Mirando a España. El ejemplo de Rusia), etc/ (Diario de Alicante", 5 mayo 1920, y "Trabajo», 9 mayo 1920, informan de la detención de un maestro de Crevillente acusado de hacer propaganda bolchevique entre los campesinos.

(67) En "El Comunista», 8 junio 1921, según MEAKER, G.H., op. cit. págs. 480482/Millá colaboraba también en «El Nuevo Orden», en 1921, según ARBELOA, V.M., La prensa obrera en España. II. 1910-1923. «Revista de Trabajo», n 31. Madrid. 1970. 
el conde Antonio Graziadei, profesor de economía y uno de los fundadores del Partido Comunista Italiano. Graziadei se entrevistó en Roma con Rafael Millá, que regresaba de Moscú (68) y, si bien llegó a España con prejuicios a favor de los ultraizquierdistas del Partido Comunista Español, la situación objetiva, tanto en el terreno nacional como en el internacional, era poco favorable a posturas tan extremadas. Después de negociar con Núñez de Arenas y Gonzalo Sanz, y de largas discusiones sobre los cargos públicos, la exclusión del nuevo partido de algunos militantes del PCOE y la composición de los órganos de dirección, Graziadei consiguió un cierto acuerdo. La secretaría general del interior del nuevo partido se encomendó a Rafael Millá (69), que también ostentaría el cargo de redactor jefe de la revista del partido, "La Antorcha». Según el propio Graziadei, en esos momentos, noviembre de 1921, las fuerzas de ambos partidos rondaban los 6.500 afiliados.

Apenas pocos días después de su nombramiento, el 18 de noviembre, era detenido en Alicante Rafael Millá, tras minucioso registro domiciliario, por órdenes de la Dirección General de Seguridad. La prensa - que comentó el hecho de diversas maneras, de acuerdo con sus tendencias ideológicas (70) - ponía en relación la detención de Millá con su reciente viaje a Rusia. "El Luchador» recogía una carta del propio Millá, escrita desde la cárcel, en la que preguntaba al Gobernador Civil por qué no habían sido detenidos Fernando de los Ríos o Daniel Anguiano, si viajar a Rusa era un delito (71). Todo esto no eran más que cortinas de humo, ya que la detención se debió, sin duda, a alguna filtración que puso en conocimiento de las autoridades la elección de Millá como secretario del nuevo Partido Comunista de España.

El nuevo partido unificado continuó gastando sus energías en disensiones internas. Ya en enero de 1922 surgieron enfrentamientos entre

(68) ARCHIVES DE JULES HUMBERT-DROZ, Origines et débuts des Partis Communistes des Pays Latins. 1919-1923. I.I.S.G. Amsterdam. 1970. Concretamente, Rapport de A. Graziadei sur la fusion des Partits Communistes d'Espagne. Págs. 113-131.

(69) Graziadei recuerda a sus camaradas del Comité Ejecutivo de la Internacional Comunista que ya habian tenido ocasión de conocer a Millá en Moscú.

(70) Para el republicano «El Luchador», la detención era un signo de los tiempos de opresión que corrian; para el liberal «El Día», Millá vino de Rusia "a últimos de septiembre y por sus ideas, era objeto de gran atención por las autoridades) (19 noviembre 1921); para el independiente, pero de extrema derecha, "Periódico para todos», Millá era un individuo muy peligroso y suponían que «su reciente viaje a Rusia ha de ser de fatales consecuencias" (18 noviembre 1921). Poco después, el Sindicato de Artes Gráficas, al que pertenecía Millá, acordaba la huelga contra «Periódico para todos» por estos comentarios, prometiendo a sus tipógrafos abonarles el salario durante el boycot. Pero los operarios de "Periódico para todos» se negaron, por lo que fueron expulsados de la sociedad obrera.

(71) «El Luchador», 24 y 30 noviembre 1921, 23 diciembre 1921. 
antiguos miembros de uno y otro partido, y se llegó a constituir el llamado «Grupo Comunista Español» (72), integrado básicamente por hombres del antiguo Partido Comunista Español, entre los cuales figuraba Rafael Millá. Cuatro de los firmantes del manifiesto de este grupo - que aseguraba, con ausencia del más elemental análisis de la realidad, que el nuevo Partido iba a "conquistar rápidamente a las masas»- , Ugarte, Andrade, Pumarega y Chicharro, fueron expulsados del Comité Central del nuevo Partido (73). El desacuerdo era fruto de antiguas rencillas, aunque se ha hablado del influjo de discusiones en torno a la participación electoral acordada por el Partido en diciembre de 1921.

En marzo de 1922, de una forma clandestina, se celebró en Madrid el congreso de unificación, del que salió el Partido Comunista de España, que

«... reuniendo en su seno la parte más avanzada y consciente del proletariado, unifica los esfuerzos de las masas trabajadoras, convirtiéndolos de la lucha por los intereses de grupo y por los resultados contingentes, a la lucha por la emancipación revolucionaria del proletariado" (74).

El nuevo Partido se estructuró por el sistema de Agrupaciones locales y de Federaciones Regionales, de las que se montaron - «mal que bien», según Artola (75) - unas cinco, entre ellas la de Levante, de la que Rafael Millá sería secretario general hasta 1923 (76).

\section{EL PARTIDO COMUNISTA DE ESPAÑA EN 1922 Y 1923}

En abril de 1922, la Komintern envió un nuevo delegado, J. HumbertDroz, para tratar de resolver el problema creado por la aparición del Grupo Comunista Español y por determinadas disensiones en el seno de las Juventudes Comunistas. Humbert-Droz, que era secretario de la Internacional para los Países Latinos, aseguraba en sus informes que había buscado vanamente un fondo político al conflicto y que apenas había encontrado disensiones más que sobre la participación en las elec-

(72) Plateforme de l'opposition du Parti Communiste Espagnol, documento 44 de los citados Archivos de Humbert-Droz. Págs. 131-138.

(73) Los expulsados escribieron a Graziadei protestando de ello: el documento puede leerse en las págs. 139-140 de los "Archives...", ya citados.

(74) TUÑON DE LARA, Manuel, El movimiento obrero en la Historia de España. Taurus. Madrid. 1972. Pág. 719.

(75) ARTOLA, Miguel. op. cit. Pág. 533.

(76) COMIN COLOMER, E. op, cit. Pág. 140: "La secretaría general de Levante correspondió a Rafael Millá, personaje destacado del revolucionarismo alicantino». 
ciones; en cambio, las cuestiones de tipo personal "sont nombreuses» (77). Se impuso la disciplina y los disidentes que no aceptaron la línea oficial del Partido fueron expulsados.

La actuación del nuevo Partido hasta la Dictadura de Primo de Rivera tuvo escaso relieve. En las zonas en que los comunistas tenían cierto peso, como Vizcaya o Asturias, hubo graves enfrentamientos con los socialistas. Los ofrecimientos formales de los dirigentes comunistas a los de otras organizaciones obreras - la CNT, los grupos anarquistas, la UGT y el PSOE - , para la formación de un Frente Unico (78), de acuerdo con las directrices de la Komintern, contrastaban fuertemente con los ataques concretos y personales a esos mismos dirigentes - así, a Largo Caballero se le calificaba de equivalente español de Noske o Mussolini-. La fuerte represión gubernamental, la debilidad teórica y el sometimiento absoluto a las directrices marcadas desde el exterior por la Komintern explican - entre otras razones - la irrelevancia del nuevo Partido antes de la Dictadura.

De otro lado, la táctica comunista de infiltración en las sociedades obreras afectas a la UGT quedó sin resultado tras los incidentes del XVV Congreso de esta central, en noviembre de 1922. La muerte de González Portillo fue utilizada hábilmente por la dirección de la UGT para eliminar a los sectores favorables a los comunistas. En un ambiente cargado de tensión, se decidió la expulsión de las delegaciones que tenían el mandato de votar el ingreso en la Profintern - equivalente sindical de la Internacional Comunista, también llamada Sindical Roja - y se amenazó con la expulsión de la UGT de esas sociedades si «se hacen solidarias de la conducta de aquellos" (79). En febrero $-y$ no en el mismo Congreso- el Pleno de la UGT acordaba la expulsión de diversas so-

(77) Pueden verse los documentos 51 (Resolution de Humbert-Droz sur le conflit intérieur du Parti Communiste Espagnol) y 52 (J. Humbert-Droz au Presidium de I'Internationale Communiste sur la situation du Parti Communiste Espagnol), en los citados "Archives...". Pags. 162-170.

(78) Lo cual suponia la lucha contra la reducción de salarios y la prolongación de la jornada de trabajo, la petición de la destitución de Martínez Anido, de la abolición de la pena de muerte, el fin de la guerra de Marruecos y la amnistía.

(79) Sobre este suceso, se montó toda una campaña de prensa contra los comunistas. Como ejemplo a nivel local -en "El Socialista" se pueden comprobar las líneas maestras - , pueden verse algunos artículos publicados en «Trabajo": Jornada sangrienta. La obra comunista (26 noviembre 1922), EI XV Congreso de la UGT y los comunistas españoles (3 diciembre 1922), En torno a la violencia (10 diciembre 1922), El respeto a la personalidad humana (17 diciembre 1922)/Según MEAKER, op. cit. pág. 582, «en todas partes de España, la prensa socialista inició una campaña que logró explotar al máximo el asesinato, esforzándose por desacreditar a los líderes comunistas, acusándoles de responsabilidad personal en esa muerte». 
ciedades obreras - entre ellas, la Sociedad de Oficios Varios de Novelda y el Sindicato Unico del Ramo de la Alpargata de Crevillente - por no haber cumplido el acuerdo del Congreso de expulsar a sus delegados, lo que se consideraba «manifestación expresa de solidaridad con acto tan execrable» (80).

Las actividades de los comunistas alicantinos entre 1922 y 1923 fueron escasas. Con ocasión del Primero de Mayo de 1922, el Partido Comunista lanzó un Manifiesto en Elche y tras hacer protestas de interés por la unidad de la clase trabajadora y reproducir las reivindicaciones formuladas por la Komintern y por el Partido, atacaba fuertemente a los dirigentes socialistas, a los que calificaba de «traidores a la causa del proletariado» (81). Por su parte, Rafael Millá proseguía incansable su propaganda entre la aletargada clase obrera alicantina (82): en las elecciones municipales de 1922, Millá se presentó por el distrito octavo de la capital y obtuvo 16 votos en dos secciones, un 1' $8 \%$ del total, lo que es buena prueba del escaso eco de sus ofertas ideológicas (83). En abril de 1923, cuando se acordó la participación del Partido Comunista en las elecciones legislativas, Rafael Millá fue uno de los veinticinco candidatos propuestos, pero al final no llegó a presentarse (84).

De los escasos grupos comunistas de la provincia - posiblemente, Novelda y Crevillente; tal vez, Castalla; con seguridad, Elche, Alcoy y Alicante - , tenemos bastante información sobre la actividad del grupo ilicitano. El de Alcoy era muy pequeño y aparece en algún acto público junto a los anarcosindicalistas. (85). El de Alicante estaba reducido prácticamente a Millá - elegido de nuevo para el Comité Central en el II Congreso del Partido, celebrado en Madrid en julio de 1923, en un ambiente cargado ya de temores a una intervención militar (86) - . Millá gozaba de cierto prestigio personal en la ciudad de Alicante - colabora en la creación del Ateneo local, por ejemplo- y tomaba parte en algunos

(80) «El Socialista», 8 febrero 1923.

(81) En $1^{\circ}$ de Mayo. Partido Comunista de España. Sección de Elche. A las masas oprimidas. En ARCHIVO MUNICIPAL DE ELCHE. Legajo 50. Documento 91./ "El Luchador», 2 mayo 1922.

(82) Conferencias en Alicante («Fases de la Revolución Rusa») y Elche en agosto de 1922.

(83) FORNER MUÑOZ, Salvador, Industrialización, clase obrera y movimiento obrero en Alicante. 1923-1936. Tesis doctoral.

(84) «El Luchador», 27 marzo 1923.

(85) En un mítin Pro-presos, que organiza el Ateneo Sindicalista, interviene por el Partido Comunista Enrique Peidró, que promete la colaboración de su Partido «a pesar de ser un pequeño núcleo» («Redención», semanario anarquista alcoyano, 27 enero 1922).

(86) ARTOLA, Miguel. op. cit. Págs. 534-535/MEAKER, G.H. op. cit. Págs: 596-602. 
actos unitarios, como el celebrado en la Casa del Pueblo, poco antes del golpe de estado, para protestar contra la aventura marroquí. (87).

En cuanto al grupo de Elche, formaban parte en él, además del ya citado Joaquín Segura, hombres como José Sánchez Pastor, Pedro Belmonte Rovira y Manuel Lozano Mendiola. (88). A mediados de 1922 se asegura que el Partido Comunista está creciendo en Elche (89), sin duda por la crisis por que atravesaba el socialismo y por la desorganización y apatía reinantes entre los alpargateros ilicitanos encuadrados en la UGT, tras las duras luchas de 1921 y 1922. Con ocasión del Primero de Mayo de 1923, la Agrupación Comunista de Elche lanzó un nuevo manifiesto "A los proletarios» (90), en la misma línea que el de el año anterior: junto a las peticiones acordadas por la Internacional Comunista, y la reivindicación del fin de la guerra de Marruecos y la promulgación de una amnistía para presos y procesados por delitos políticos y sociales, hay una fuerte crítica a los socialistas:

«Sostened en su lucha intrépida a los partidos comunistas, que os trazan el camino de la emancipación y os preceden en la marcha, exponiéndose los primeros a los furores de las represalias de la burguesía... Hoy más que nunca se hace de imprescindible necesidad que el proletario todo, forme el frente único preconizado por la Internacional Comunista y la Internacional Sindical Roja frente a todos los socialistas reformistas y traidores a la revolución proletaria, aliados de la burguesía».

Los comunistas de Elche, junto a los sindicalistas, llevaron a cabo una feroz campaña contra los socialistas: los insultos que se intercambian (91) sustituyen a los análisis de la realidad y a las elaboraciones más o menos teóricas. Hay que tener en cuenta, además, que la aparición de un «Sindicato Trabajadores de Elche y su Radio» y del "Sindicato Unico del Ramo de la Piel», promocionados por comunistas y sindicalistas, amenazaba la tradicional hegemonía socialista en el Círculo Obrero llicitano y entre la clase obrera de Elche.

(87) «El Luchador», 10 septiembre 1923.

(88) "Trabajo», 10 diciemrbe 1922.

(89) «El Luchador», 10 julio 1922, afirma que el Partido Comunista cuenta en Elche «con muchas simpatías").

(90) ARCHIVO MUNICIPAL DE ELCHE. Legajo 50. Documento 103.

(91) Se podría hacer una lamentable antologia de los insultos que se intercambian socialistas y comunistas: pueden verse las páginas de "Trabajo» (por ejemplo, Lógica comunista, 17 junio 1923/ i Infames! Otro socialista asesinado, 1 junio 1923/Esa es vuestra obra, 6 septiembre 1923), y los panfletos de la Agrupación Comunista de Elche, que se conservan en el ARCHIVO MUNICIPAL DE ELCHE, especialmente el titulado La Agrupación Comunista a la clase trabajadora de Elche, fechado el 3 de julio de 1923. 
En los meses anteriores al golpe de estado de Primo de Rivera, e incluso en los días previos, el Partido Comunista de Elche llevó a cabo diversas actividades, centradas sobre todo en la lucha contra la guerra de Marruecos.

«...para demostrarle a los Poderes contituidos que la clase trabajadora, por ninguno de los conceptos quiere continúe esa vil aventura marroquí, la cual se ha invertido (sic) en antro de explotación de la juventud obrera española, causando el dolor y la miseria en los hogares proletarios, donde las afligidas madres lloran y sufren perpetuamente por el hijo que murió o espera que le maten en tierras africanas por defender lo que llaman patria, que sólo es el egoismo de unos aventureros sin conciencia). (92)

Y en la demanda de una amnistía para los presos sociales: así un acto "pro Procesados Dato y Contra el Terrorismo», en julio de 1923 -junto al Grupo de Afinidad Sindicalista, y con la adhesión del Sindicato del Ramo de la Piel, Sindicato del Ramo de la Construcción, del Sindicato del Ramo Textil, Sociedad de Trenzadores de Yute, Sociedad de Panaderos y Grupo Cultural Proletario, lo que nos da un panorama de la influencia sindical de sindicalistas y comunistas (93) - , y una conferencia, a primeros de septiembre, de Rafael Millá, sobre "Colaboracionismo y lucha de clases», a la que se invitaba "a todos los desheredados de la fortuna», para mostrar su solidaridad con los presos sociales (94).

En vísperas de la Dictadura, el Partido Comunista era a nivel estatal, un «núcleo confuso, orgánica e ideológicamente», según la acertada opinión de Tuñón de Lara. El diagnóstico sirve también para la provincia de Alicante. En los primeros momentos de la.Dictadura, se ejerció cierta presión contra comunistas y sindicalistas - con detenciones en Crevillente y Denia, por ejemplo-, que eran metidos en un mismo saco por las autoridades militares. Por el contrario, como es sabido, la Dictadura será una época en que los socialistas, a nivel general y en concreto en comarcas como el Bajo Segura o los Valles de Vinalopó, se consolidarán fuertemente, gracias a la tolerancia de las nuevas autoridades y a cierto colaboracionismo, de fonema que, a la llegada de la República, la hegemonía entre la clase obrera alicantina - con alguna excepción, co-

(92) Acto que organiza en septiembre de 1923 la Juventud Comunista ilicitana: ARCHIVO MUNICIPAL DE ELCHE. Legajo 50. Documento 128. En este mismo panfleto, se hace un llamamiento "contra el fascismo".

(93) ARCHIVO MUNICIPAL DE ELCHE. Legajo 50. Documeneto 116.

(94) ARCHIVO MUNICIPAL DE ELCHE. Legajo 50. Documento 125. 
mo Alcoy - había vuelto a las manos de los socialistas, que la habían ostentado desde primeros de siglo.

\section{CONCLUSIONES.}

El desarrollo primitivo del Partido Comunista de España tiene unas características comunes con el resto de los paises europeos, pero a la vez posee otras que le son propias. La Internacional Comunista partía de la creencia en la inminencia de una revolución mundial que habría de desarrollarse de modo semejante a lo ocurrido en Rusia: de ahi, que el «modelo bolchevique» pasara a ser considerado como un "modelo universal», lo que por fuerza fué causa de graves errores en los nacientes Partidos Comunistas europeos: «táctica insurreccionalista, dependencia dogmática del modelo bolchevique, priorización de la dinámica internacional impuesta desde la cumbre de la Internacional sobre la dinámica nacional, sectarismo respecto a las otras corrientes del movimiento obrero" (95).

De otro lado, a partir de 1920, desapareció en toda Europa cualquier posibilidad de revolución a corto plazo y se produjo, por el contrario, un evidente reflujo en el movimiento obrero internacional, que incidió con un deterioro en el avance hacia la construcción del socialismo en Rusia y la postergación de los métodos leninistas en la organización interna de la Komintern.

En España hubo causas de tipo estructural y coyuntural que contribuyeron al escaso eco de la oferta ideológica comunista entre la clase obrera: entre otras, el lento crecimiento industrial del país; el hecho mismo de que el Partido Socialista se encontrase mucho menos desprestigiado que otros europeos, por no haber tomado parte en la Guerra Mundial; la aparición más tardía en España de los Partidos Comunistas, cuando ya se había amortiguado un tanto el impacto emocional de la Revolución Rusa y se asistía, en cambio, a un aumento de la reacción; el importante papel jugado por Pablo Iglesias, con su inmenso prestigio en las filas socialistas; la conservación, por parte de la Confederación Nacional de Trabajo, de una clara «imagen revolucionaria» entre los obreros españoles, imagen que fue desperdiciada por la acción combinada del terrorismo y la represión; la no coincidencia entre la lucha obrera de las ciudades y la agitación campesina; la solidez del aparato coercitivo del estado, comprobada en la huelga de 1917, cada vez más intervencionista en la vida civil, etc. En suma, la oferta del Partido Co-

(95) ESTRUCH, Joan. op. cit, pág. 35. 
munista cayó en "un vacio ideológico" y tuvo que esperar mejores circunstancias (96).

En la provincia de Alicante, el Partido Comunista surgió y se desarrollo en un principio prácticamente ligado a la persona de Rafael Millá, y no pudo o no supo conectar con la clase obrera organizada de la provincia: ni con los sectores dominados por los sindicalistas, como el Textil alcoyano, el movimiento obrero de Elda o los trabajadores del Puerto, los transportes y los almacenes de la capital, movilizados por el Sindicato Unico entre 1919 y 1920; tampoco en otros núcleos obreros, que controlaba la Unión General de Trabajadores, tuvieron éxito los esfuerzos de penetración del Partido Comunista: ni en el sector alpargatero de Elche, pese a todo, ni en el reducto ugetista de Villena -que precisamente en estas fechas logró crear una fuerte organización de campesinos-, ni en otras localidades del Vinalopó Medio. Además de las ya apuntadas, las causas fueron una larga tradición reformista, favorecida por la escasa conciencia de clase de un proletariado que, aún en 1923, trabajaba en muchas localidades a destajo y con jornadas superiores a las ocho horas; la grave crisis de trabajo en los primeros años veinte, y el agotamiento de los sectores más combativos del proletariado alicantino tras las duras luchas de 1919 y 1920 . En suma, la oferta comunista, con su «discurso» claramente importado, tenía lógicamente que encontrar escaso eco, por su exotismo, entre los trabajadores alicantinos y españoles.

(96) MEAKER, G.H. op. cit. págs. 610-616. 


\section{APENDICE}

\section{«MACHACONERIAS"}

Si de las ideas se pudiera hacer un análisis fisiológico, cual se hace del cuerpo humano, el mundo habría resuelto el problema primordial que tiene ante sí, el único que con toda urgencia necesita aclarar. Se vería cómo ciertos individuos que se precian de tener ideales muy nobles y elevados, en vez de ideas, lo que tienen es un conglomerado de ilusiones vagas y estrambóticas, inarmónicas, incapaces de darlas ilación e inaplicables a un fin práctico.

Ahora, con eso de la revolución rusa, se ha armado aquí en España - país de las vehemencias - un cambio tan radical en el orden ideológico que, estaba por afirmar, no se entiende ni Cristo. Socialistas que antes de este acontecimiento permanecian haciendo labor constructiva, dedicada exclusivamente a engrosar las filas de nuestro partido - que es lo único que debe hacerse - sin fijarse en calificativos más o menos radicales, se han dado cuenta, algo tarde, que la salvación de la humanidad está en la dictadura del proletariado. ¡Dictadura! Palabra esta que se presta a un minucioso examen y hacerlo intentaremos. Como hasta los momentos actuales el obrero manual ha sido el que verdaderamente ha luchado por su mejoramiento de clase, $y$ al decir obrero manual, entiéndase el obrero rudo, inculto, él y sólo él se cree con derecho a ejercer la dictadura que no implantará nunca, que no obtendrá los goces de ella, porque para ello necesita lo que no tiene: cultura. No es posible que un obrero por voluntad que tenga, por sacrificios que se imponga, que, después de las horas que durante el día ha empleado para ganar el sostén de él y de los suyos, le quede tiempo para ilustrarse y cultivar su inteligencia, lo suficiente para regir los destinos de un pueblo, de un estado, del mundo... Tiene perdón, se puede disculpar todo intento de asalto a la dictadura que el proletariado, tal como hoy se entiende, quiera ejercer. Sobrada y muy sobrada razón tiene para ello. ¡Es tanta la indiferencia que se observa en aquelias clases que debieran estar con nosotros y que creen pertenecer a otra esfera más alta! Nosotros los socialistas, aunque se nos considere por ciertos elementos como incapaces de razonar, estamos convencidos que no somos los obreros manuales los llamados a regir los destinos de España y del mundo. Quédense con esas suposiciones los anarquistas apócrifos, capaces de montar un edificio de seis pisos sobre una base de bizcochos. La clase dirigente, la llamada a ponerse al frente de los destinos del mundo es, todo ese enjambre de burocracia que hoy permanece inmóvil: el maestro elemental y el catedrático, los cuerpos de correos y telégrafos, empleados de Hacienda, los ingenieros y tantos otros que, si depender del Estado, se hallan en condiciones muy semejantes.

El dia que estas clases abandonen el indiferentismo en que se hallan, será la hora indicada para la revolución. Mientras, todo intento será nulo, todo esfuerzo frustrado, expuestos a que, en vez de una horra de justicia, tengamos dias y años de guerra civil, lo más denigrante que pueda registrar la historia de los pueblos.

Una demostración de que no será muy halagüeño para el proletariado inculto erigirse en dictador, lo prueba el telegrama dirigido por el primer bolchevique ruso, Lenin, al proletariado inglés, considerado por el mundo entero como el más capacitado:

«Si podéis conseguir en Inglaterra que la revolución sea pacifica, nadie lo celebrará tanto como nosotros en Rusia. Disciplinaos en los Sindicatos. Disciplinaos en el movimiento obrero. No os dividáis antes de que sea forzoso dividirse. No os disgreguéis por huelgas o levantamientos prematuros. Permaneced unidos todo el tiempo que podáis. No os dejéis llevar demasiado pronto a la violencia».

Este telegrama, al que al mismo autor no pone ningún comentario, demuestra la labor abrumadora que, sobre él y los demás que están al frente de aquella vasta nación, pesa. Demuestra también que en Rusia se ha hecho la revolución inesperadamente, obligada 
por las circunstancias y que en Rusia, como aquí, existe la división entre los trabajadores y que es un perjuicio para la causa proletaria que haya diversidad de apreciaciones.

¿Qué sería del pueblo español, tan vanidoso, tan egoista, tan personalista, si por la fuerza de las circunstancias se viera abocado a una revolución? Anarquistas por una parte, socialistas por otra, republicanos por otra... el caos.

Tomen buena nota los atacados de dictadura de los consejos de Lenin; no crean que eso de la revolución es coser y cantar. "Disciplinaos en el movimiento obrero...". "No os disgreguéis por huelgas o levantamientos prematuros». "Permaneced unidos todo el tiempo que podáis". "No os dejéis llevar demasiado pronto a la violencia».

Estas palabras, a ser posible, se las colgariamos de la nariz a todos los atacados que censuran la pasividad de los hombres de nuestro partido. No se dejen llevar los socialistas españoles por alharacas rusas y estridencias anarquistas. Dejad que los anarquistas, ellos entre sí, se rompan el alma, que bien merecido lo tienen.

Pongan bien expuestas, a modo de plano, las ideas que abrigan y analicenlas, vean la realidad en que se hallan, el grado cultural de los dirigidos, el tanto de moral que tienen el pueblo o pueblos a quienes se incita a la revolución y entonces vuelvan la vista a las ideas y al plano y verán los individuos de ideas nobles y elevadas que lo que tienen no son tales, sino ilusiones.

Miguel

(«El Mundo Obrero». 10 abril 1920)

\section{"DEFENSA DE LA DICTADURA"}

\section{Para mi querido a.nigo y compañero de Redacción MIGUEL.}

Tu artículo del último número de EL MUNDO OBRERO me ha producido un efecto deplorable.

Yo te quisiera más enterado de las cosas para que no te quedaras tan rezagado en este bello alborear de profundas y radicales transformaciones en la ideología que informa a los núcleos obreros.

No son «ilusiones vagas y estrambóticas» lo que tenemos aquellos que estamos inquietados por las cosas que pasan en el mundo, sino ideas bien definidas y capaces de ser aplicadas a un fin práctico.

Voy a ver si sé explicarme y darte la sensación de la verdad de lo que digo.

Eso de Rusia que tú desdeñas así olimpicamente y calificas de alharacas, es un poco más importante de lo que tú te figuras y capaz por si sólo de perturbar ese statu quo del Partido que tanto lamentas se altere porque debiamos seguir consagrados a «engrosar las filas del Partidon.

Lo de Rusia, amigo, es el triunfo del socialismo, la encarnación real de nuestros ideales, algo que veíamos muy lejano y que de pronto se presenta ante nuestros ojos deslumbrante de belleza y majestad. Es la experiencia hecha por un proletariado hermano con una táctica de lucha, en cuyos resultados hemos de estudiar mucho los socialistas de todos los paises.

No es que nos hayamos acordado ahora de que la redención está en la dictadura del proletariado, sino que hasta después del triunfo de la revolución rusa no habiamos tenido motivo para discutir sobre el asunto porque nos parecía un sueño que los hombres de la actual generación fuéramos los que tenían que dar solución a ese problema. 
Has ido un poco lejos al hablar en nombre de los socialistas para sentar la afirmación de que estamos convencidos que no han de ser los trabajadores manuales los llamados a regir los destinos del mundo.

La dictadura, mi amigo, no han de ejercerla los obreros intelectuales o los manuales, sino una minoría inteligente, se encuentren los individuos catalogados entre los intelectuales o manuales. Afirmar que sólo los intelectuales están capacitados para regir los destinos de la humanidad, es tanto como condenar a una supeditación eterna del proletariado a la burguesía, pues para nosotros estarán siempre cerradas las Universidades mientras dominen los ricos y además los capitalistas tendrán siempre - mientras dure su hegemonía - sometidos a su tiranía a la inmensa mayoria de los intelectuales, ya que tienen acaparados los Bancos, las Universidades, la Prensa, todo aquello, en fin, en donde emplean sus actividades los obreros del cerebro.

Ten en cuenta que si los rusos tuvieran que haber esperado para hacer su revolución a contar con los intelectuales burócratas, todavia estarian sufriendo los rigores del zarismo, pues habrás de recordar cómo esta clase de obreros negó su concurso al régimen sovietista en los primeros meses de su implantación.

La implantación de la dictadura no es un capricho para que ello resulte halagüeño, sino una necesidad histórica a la que no podremos sustraernos los trabajadores si de veras queremos emanciparnos. "La dictadura del proletariado - escribe Lenin en su libro Democracia burguesa y democracia proletaria - no significa una forma de gobierno, sino un Estado de naturaleza particular, el Estado proletario, es decir, un mecanismo para aterrar a la burguesía, ya que se opondrá siempre con furor a su expropiación». Y para la creación de ese «mecanismo", en Rusia no se han esperado a que quisieran los intelectuales, ni está formado con éstos elementos solamente, sino que se ha procurado apoyarlo en las masas profundas del proletariado industrial $y$ en los campesinos pobres.

Te irrita que nos dividamos y nos citas el mensaje de Lenin a los proletarios ingleses para convencernos a los atacados que censuramos la pasividad de los hombres de nuestro Partido. No te incomodes.

En primer lugar, que tenemos serios motivos para no creer en la paternidad que se atribuye a ese mensaje. Lenin no puede haber escrito eso. El hombre que ha inspirado la creación de la Tercera Internacional, que combate sin piedad a todos los oportunistasreformistas del Socialismo, que excita a la creación de partidos comunistas separados de los Partidos Socialistas históricos, no puede aconsejar al proletariado inglés que no se divida todavía. Lee el artículo de Lenin La revolución proletaria y el renegado Kautsky y verás cómo acusa de reformista al Partido Independiente inglés y le atribuye una mentalidad de pequeño burgués y nacionalista, cosas ambas para que no lo considere como instrumento adecuado para hacer la revolución. Además lee la prensa y te enterarás como apoyado por el Comité Ejecutivo de la Tercera Internacional, ya se está fundando el Partido Comunista de Inglaterra.

Por otro lado una división ideológica no es nada malo, es síntoma de crecimiento, es enfermedad que se ha dado en todos los partidos hermanos del mundo y el nuestro no podía ser una excepción; denota que los socialistas españoles comienzan a pensar por cuenta propia y que los que ya lo hacen no renuncian a ello por esa añagaza de la unidad.

A todos los que os asusta lo de la dictadura del proletariado habrá que recordaros que actualmente el poder de la burguesía no está cimentado sino en la dictadura del capitalismo contra el proletariado, siquiera esté disfrazada su forma violenta con la «máscara de la democracia», antifaz con que encubre el régimen, a los ojos de los incautos, toda la trabazón arbitraria sobre que está asentado. Además, tened en cuenta que la dictadura capitalista no está basada en el predominio de los más inteligentes, sino de los más ricos, aunque sean los más brutos y que representan la dominación de unos pocos sobre la inmensa mayoría de la población que está formada por los obreros y los campesinos pobres; todo lo contrario que nuestra dictadura, que aún cuando tuviese el defecto de ser ejercida por 
los obreros manuales solamente, tendría indudablemente la ventaja de justicia a favor dé ser el predominio de los más sobre los menos, que son los actuales dominadores.

Medita, compañero, sobre todas estas cosas, y considera si los que asi pensamos tenemos ideas inarmónicas e ilusiones vagas, o estamos dominados por una gran inquietud intelectual, precursora de ideales fecundos, al servicio de la gran causa de los oprimidos.

Rafael MILLA

(«El Mundo Obrero», 17-abril-1920) 